\title{
Encontros e percursos de professoras militantes: Hildézia de Medeiros e Dodora Mota
}

\author{
Meetings and paths of militant teachers: \\ Hildézia de Medeiros and Dodora Mota
}

Encuentros e caminos de maestras militantes:

Hildézia de Medeiros y Dodora Mota

Lia CIOMAR MaCEDo de Faria (iD)

THAÍS RODRIGUES MARTINS

\section{Resumo}

O artigo se propõe a analisar os trajetos de vida de Hildézia Alves de Medeiros e Maria das Dores Pereira Mota, com o objetivo de perscrutar seus processos de formação inicial, o encontro entre ambas e sua repercussão em seus caminhos. A temática abordada - trajetória e formação de docentes engajadas - propõe como questão a necessidade de conhecer essa dimensão da trajetória de mulheres professoras para compreender como se forjaram suas concepções e atuação em prol da educação pública, bem como se constitui como contribuição para pensar os dilemas atuais através de olhares sobre percursos formativos de professoras militantes. Importantes lideranças sindicais do SEPE, Sindicato Estadual dos Profissionais de Educação, e professoras das Redes Públicas de Ensino no Estado do Rio de Janeiro, ambas tiveram atuação fundamental na luta pela democratização da educação pública. Considerando como perspectiva metodológica a história oral, foram utilizadas como fontes principais entrevistas

a Universidade do Estado do Rio de Janeiro (UERJ), Rio de Janeiro, RJ, Brasil. Doutora em Educação, e-mail: liafolia11@gmail.com

b Universidade do Estado do Rio de Janeiro (UERJ), Rio de Janeiro, RJ, Brasil. Mestre em Educação, e-mail: tha.isismar@gmail.com 
realizadas no contexto de projetos e debates desenvolvidos por nosso laboratório de pesquisa, que vem coletando e sistematizando memórias no intuito de aprofundar estudos sobre trajetórias de docentes e lideranças sindicais do magistério do Estado do Rio de Janeiro. Revisitar as memórias e processos de formação e autoformação dessas mulheres, compreender sua atuação militante e sua opção de vida comprometida com a transformação social e a construção democrática, mesmo em tempos de ditadura civil-militar, contribui significativamente para pensar a superação dos desafios e retrocessos dos tempos pandêmicos atuais.

Palavras-chave: Educação de mulheres. Sindicalismo docente. História da Educação.

\section{Abstract}

The article proposes to analyze the life trajectories of Hildézia Alves de Medeiros and Maria das Dores Pereira Mota, with the objective of examining their initial formation processes, their encounter and its repercussions on their paths. The theme addressed trajectory and training of engaged teachers - raises as a question the need to know this dimension of the trajectory of female teachers in order to understand how their conceptions and performance in favor of public education were forged, as well as constituting a contribution to thinking about the dilemmas and their current perspectives on training paths of militant teachers. Important union leaders from SEPE (education professionals union), both played a key role in the struggle for the democratization of public education. Considering the oral history as a methodological perspective, interviews were conducted in the context of projects and debates developed by the research laboratory, which has been collecting and systematizing memories in order to deepen the research about studies on the trajectories of teachers and union leaders the State of Rio de Janeiro. Revisiting the memories and processes of formation and self-formation of these women, understanding their militant role and their choice of life committed to social transformation and democratic construction, even in times of civil-military dictatorship, contributes significantly to thinking about overcoming the challenges and setbacks of current pandemic times.

Keywords: Women Education. Teaching unionism. Education History.

\section{Resumen}

El artículo analiza las trayectorias de vida de Hildézia Alves de Medeiros y Maria das Dores Pereira Mota, con el objetivo de evidenciar sus procesos de formación inicial, el encuentro entre ambas y su repercusión en sus caminos. Esta temática - trayectoria y formación de docentes comprometidas - propone como cuestión la necesidad de conocer esa dimensión de la trayectoria de mujeres profesoras para comprender cómo 
se desarrollaron sus actuaciones en pro de la educación pública, así como se constituye como contribución para pensar los dilemas actuales a través de miradas sobre los recorridos de la formación de profesoras militantes. Importantes liderazgos sindicales de SEPE, Sindicato Estadual dos Profissionais de Educação, e profesoras de las Redes Públicas de Ensino en el Estado de Río de Janeiro, ambas actuaron fundamentalmente por la democratización de la educación pública. Considerando como perspectiva metodológica la história oral, utilizamos como fuentes principales entrevistas realizadas en el contexto de proyectos y debates desarrollados por nuestro laboratorio de investigación, que ha reunido memórias para profundizar los estudios sobre las trayectorias de docentes y liderazgos sindicales del magisterio del Estado de Río de Janeiro. Revisitar las memorias y los procesos de formación y autoformación de esas mujeres, comprender su actuación militante y su opción de vida comprometida con la transformación social y la construcción democrática en tiempos de dictadura civilmilitar, contribui significativamente para pensar la superación de los desafíos y retrocesos en los tiempos pandémicos actuales.

Palavras-clave: Educación de mujeres, Sindicalismo docente, Historia de la educación.

\section{Introdução}

Haverá vontade de pensar em alternativas quando a alternativa que se busca é a normalidade que se tinha antes da quarentena? Pensar-se-á que esta normalidade foi a que conduziu à pandemia $e$ conduzirá a outras no futuro?

(Boaventura de Sousa Santos, 2020, p. 30).

Pensar alternativas de futuro sempre foi tarefa para as sonhadoras e sonhadores. No mundo pandêmico em que vivemos hoje, em pleno século XXI, torna-se um desafio sem igual.

Boaventura (2020) nos provoca a ir às entranhas dessa reflexão quando pergunta se, ultrapassada a fase mais crítica da pandemia em que o planeta se encontra, queremos voltar à normalidade de um mundo que se orientava e organizava, predominantemente, por um sistema que sempre produziu desigualdade, injustiça e sofrimento.

$\mathrm{Na}$ angústia de quem vive pela primeira vez as restrições e dores causadas por um processo de disseminação global de um vírus para o qual a ciência ainda não 
possui remédios ou vacinas, considerando que as gerações que testemunharam outros episódios dessa proporção já não estão aqui, todos desejam o fim dessas condições e, portanto, a retomada da vida "normal".

No entanto, essa normalidade, desejada por muitos e denunciada por Boaventura, era por si só produtora de angústia e sofrimento naqueles e naquelas a que o modo capitalista em operação tratava por invisíveis, rejeitados, oprimidos, excluídos, verdadeiros resíduos da humanidade, de quem apenas se extrai valor ao máximo, sem nenhuma contrapartida que garanta dignidade e vida plena.

E foi exatamente essa normalidade já existente pré-pandemia que motivou, em algum ponto da trajetória de mulheres como Hildézia e Dodora, uma escolha de vida. Mulheres de uma época em que era condenável ser mulher pensante, autônoma, sindicalista, política e lutadora social. Mulheres professoras engajadas, despertadas para o exercício de uma consciência política de classe e para a prática sindical militante, sempre associada ao sonho de construção de uma alternativa que subvertesse o projeto de sociedade hegemonizado pelo Capital. Mulheres cuja trajetória pessoal imbrica-se às coletividades que as perfizeram no correr da história. História essa em que seus caminhos se cruzam justamente a partir da atuação sindical, numa relação em que uma se constitui referência da outra e a troca formativa se dá intensamente.

É, portanto, das trajetórias e percursos formativos dessas mulheres, professoras e sindicalistas do ensino básico público no Estado do Rio de Janeiro, a nordestina Hildézia Alves de Medeiros e a mineira Maria das Dores Pereira Mota (Dodora), que trataremos neste artigo.

Como nos diz Mário de Andrade (1980, p. 29), “O passado é lição para se meditar, não para reproduzir”. As pesquisas desenvolvidas sobre memórias docentes e trajetórias de mulheres contribuem, também, para repensar a educação fluminense e a formação de professores/as no período da redemocratização política brasileira, na década de 1980.

Conforme Tavares e Bragança (2016, p. 75), “tendo o território material e simbólico como um campo de forças, no qual objetivamente e subjetivamente são reconstituídos o ethos profissional docente, melhor dizendo, os diferentes modos de ser professor(a)". Deste modo, compreendemos que o exame das ações políticas 
docentes, nas décadas de 1970 e 80, pode auxiliar não só na ordenação dos vestígios de um passado ainda recente, mas também proporcionar uma releitura dessas pistas, já que os esquecimentos e silêncios da história são reveladores desses mecanismos de manipulação da história coletiva.

A relevância do tema se expressa, também, pela importância estratégica ocupada pela instituição Escola no projeto republicano e sua dimensão sociocultural, na constituição política da sociedade brasileira. Assim, entendemos que tais memórias, narrativas docentes acerca das décadas 1970-80, assinalem possíveis marcas e influências na matriz identitária do professorado, com destaque à participação feminina. Logo, nosso laboratório de pesquisa vem aprofundando o estudo sobre as duas lideranças sindicais já citadas, expressivas personalidades do magistério fluminense e muito atuantes no sindicalismo docente do estado do Rio de Janeiro.

Como metodologia, trabalhamos na perspectiva da história oral, utilizando de entrevistas realizadas nas pesquisas de mestrado e pós-doutoramento, considerando os procedimentos éticos devidos no campo das ciências sociais e humanas, bem como o consentimento das entrevistadas. Através das fontes orais, no fazer da coleta e análise de memórias e informações, exploramos como referência para compreensão desse trajeto metodológico Aceves Lozano (1998):

Nesse estilo de trabalho, a tarefa de produzir conhecimentos históricos se torna válida, especialmente rica e atual, já que implica: reflexão teórica, trabalho empírico e de campo; maior ligação e vínculo pessoal com os sujeitos estudados; um processo de constituição de uma fonte e um processo de produção de conhecimentos científicos... (LOZANO, 1998, p. 24).

Ao decidirmos trabalhar com trajetórias de vida, investindo nas fontes orais, compreendemos também estar perpassando a história comunitária e social de coletivos com os quais Hildézia e Dodora interagiram. Considerando Lelis e Nascimento "Busca-se com as histórias de vida, atingir a coletividade de que seu informante faz parte" (2010, p. 255). Cabe destacar ainda a contribuição dos estudos de Libânia Xavier à História da Educação e à temática do associativismo e participação docente. 
Em tempos de governos extremamente conservadores eleitos no Brasil no último pleito (2018), tornam-se de extrema relevância investigações que desvelem, no passado, narrativas e memórias dos sujeitos e/ou atores sociais atuantes politicamente, em particular no que se refere à luta pela educação pública e seu professorado. Por fim, trata-se de criar condições para denunciar ofensivas antidemocráticas que possam vir a atingir nossas escolas e universidades públicas nos tempos atuais em nosso país.

\section{Hildézia de Medeiros — militância política no/do feminino}

Posto o limite fatal que o tempo impõe ao historiador não Ihe resta senão reconstruir, no que for possivel, a fisionomia dos acontecimentos (Ecléa Bosi, 1979, p. 21).

Hildézia Alves de Medeiros, mulher, professora negra e nordestina, desponta como a principal dirigente sindical do SEPE (Sindicato Estadual dos Profissionais da Educação - RJ) entre as décadas de 1970 e 1980. Em alguns de seus depoimentos, ao longo da nossa pesquisa, rememora sua formação religiosa e protestante, na Igreja Batista, ainda no nordeste. Quanto àquelas práticas, confessionais, as definiu como marcadas pelo fanatismo e intolerância.

Nossa protagonista nasceu em 19 de agosto de 1940, na cidade de Salgueiro, interior de Pernambuco, terra de solo rachado e povo maltratado pela seca. Hildézia vem para o Rio de Janeiro no início dos anos 1960. O motivo que a trouxe para o Sudeste seria uma oportunidade oferecida pela Igreja Batista para que dirigisse uma revista para jovens, e na ocasião faria um curso de formação religiosa.

Isso nos faz refletir qual teria sido o pontapé inicial, de que forma as suas insatisfações com as estruturas da sociedade fizeram com que a jovem do interior, buscando formação religiosa, se tornasse uma grande militante que mais tarde teria destaque como dirigente sindical do SEPE.

Hildézia não se casou, nem teve filhos. Hoje, com 80 anos, ainda atua como militante política no Partido dos Trabalhadores (PT). Em especial, nos movimentos em defesa dos negros, mulheres, LGBT, sempre priorizando a luta pela educação 
pública. Também se assinala em suas narrativas como a educação das mulheres até os anos 1960/70 ainda era voltada ao casamento e à maternidade, com exceção para a carreira do magistério, que seria a esperada profissão feminina.

Logo, as pesquisas sobre memórias docentes e trajetórias de mulheres contribuem para repensar a educação de professores/as. Trata-se do "inventário" de uma geração, buscando marcas e vestígios das ideologias e utopias que circulavam no imaginário social e político das professoras do estado do Rio de Janeiro naquele período.

Portanto, conforme Perrot (2007, p.16): "Escrever a história das mulheres é sair do silêncio em que elas estavam confinadas". O que a pesquisa revela é que tais espaços "femininos", como a casa e a escola, muitas vezes se apresentam também como territórios de opressão e exclusão social.

Nossa entrevistada destacou o fato de o magistério público fluminense possuir dois sindicatos, a UPPE (União dos Professores Públicos Estaduais/RJ) e o SEPE, sendo o primeiro com um matiz mais conservador, o que revela possíveis contradições das mulheres professoras atuantes na educação básica do sistema público estadual do ensino fluminense.

Deste modo, ao sair da esfera privada da família e ingressar na esfera pública através da escolarização e do trabalho, essas mulheres abrem possibilidades de superação de sua própria alienação, imposta pela tradicional condição feminina.

Hildézia, ao vir para o Rio de Janeiro nos anos 1970 a convite da Igreja Batista para exercer um cargo de coordenação, decide, após algum tempo, abandonar as atividades religiosas e iniciar militância política nas lutas pela redemocratização brasileira.

Também trabalhou com publicidade no período que antecede sua participação no projeto Mobral $^{1}$, que oferecia Educação para jovens e adultos em

\footnotetext{
${ }^{1}$ Um dos principais pontos problemáticos sociais que era necessário erradicar no Brasil era o analfabetismo. O Mobral (Movimento Brasileiro de Alfabetização), movimento criado durante a ditadura militar a fim de alfabetizar pessoas (jovens e adultos) não letradas, tinha a intenção de estancar um problema social que vinha se alastrando desde o Império Brasileiro. Ver: BEISIEGEL, Celso de Rui. A política de educação de jovens e adultos
} 
amplitude nacional — movimento do qual teria sido expulsa por não concordar com seu viés conservador. Após esse período de vivências teóricas e práticas no campo educacional, inicia sua carreira como servidora do Estado, tendo lecionado na Escola Tiradentes, em Cachoeiras de Macacu. Em seguida, sua trajetória educacional também perpassa pela atuação na Secretaria Estadual de Educação do Rio Janeiro.

Em 1977, ela ingressa para cursar História na UFF (Universidade Federal Fluminense), enfrentando grandes desafios, reafirmando sua busca pela equidade social. Na UFF fez parte do MEP (Movimento de Emancipação do Proletariado). É através da sua participação na organização que surge a necessidade da criação de um movimento de luta do magistério do Rio de Janeiro, uma vez que quem fazia parte do funcionalismo público na época, não poderia estar vinculado a uma organização sindicalista.

Fruto destas inquietações, necessidades de mudança e de garantia de direitos básicos, surge, em 1977, o SEP (Sociedade Estadual dos Professores), que teve sua primeira reunião realizada na PUC-Rio, buscando estratégias de organização para usar, de forma articulada, a educação como ferramenta de enfrentamento às opressões da ditadura naquele momento. Em 24 de julho de 1979, o SEP se funde com a União de Professores do Rio de Janeiro (Uperj) e com a Associação dos Professores do Estado do Rio de Janeiro (Aperj), tornando-se CEP - Centro de Professores do Rio de Janeiro, uma entidade que se torna referencial de luta e organização dos educadores fluminenses. Neste mesmo ano, mais fortes e organizados, conquistam um piso salarial para os profissionais da educação equivalente a cinco salários mínimos, após uma greve histórica do movimento, que também teria sido estopim para reivindicações de outros setores.

Logo, a importância de pesquisas no campo da história da educação reside no fato de que a escola também contribui para a construção do professorado enquanto sujeito histórico.

analfabetos no Brasil. In: Gestão democrática da educação: desafios contemporâneos. [S.I: s.n.], 2005. 
Deste modo, o texto ressalta também, como dimensão de formação e autoformação, a participação das professoras de educação básica no processo de democratização da escola pública, assim como na organização dos movimentos associativos de classe, até então proibidos pelos governos autoritários. O que podemos observar pelas fontes já investigadas, em periódicos e fotos de época, é a presença marcante da nossa investigada, reafirmando sua forte liderança.

Portanto, o estudo vem fazendo uso de fontes orais, documentais e bibliográficas, por meio das quais investiga o processo formativo dessas mulheres, educadoras e militantes, através de suas trajetórias pessoais.

Quando à frente da diretoria do SEPE, nos anos 1980, em uma de suas entrevistas, Hildézia relembrou que esteve na organização de cursos no SEPE para discutir a questão de gênero, do corpo e da sexualidade. Naquele momento, afirma que tal iniciativa foi entendida como "meio escandaloso para algumas pessoas". O que teria ocorrido, de acordo com suas memórias, entre 1984 e 1988.

É, pois, nesse mesmo período que conhece Dodora Mota, também professora militante do interior do Estado. Ao compartilharem momentos fundamentais de organização de classe profissional, nas muitas reuniões, assembleias e manifestações estabeleceram identificação e admiração mútua, embora Hildézia fosse mais experiente e sua liderança abrangesse parcela maior da categoria, representando, para Dodora, também um exemplo de liderança. No curso dessa relação, como membro da diretoria do SEPE/RJ, Hildézia contribui para a criação de uma exposição que revelava a condição de opressão de gênero a que a imensa maioria da categoria do magistério estava submetida, indicando Dodora para protagonista desse trabalho, que se intitulou "O sol por testemunha" (1987), com texto de Isis Baião e fotografia de Cláudia Ferreira.

A partir desse olhar sobre o passado, Hildézia também destacou um avanço fundamentalista na sociedade, se referindo ao fenômeno do crescimento do neopentecostalismo no campo das religiões no Brasil, elemento que guarda similaridades com os dias atuais. Para Hildézia, não só a escola pública, mas as professoras das séries iniciais vêm sendo bastante influenciadas por essa nova onda religiosa, a seu ver, com fortes traços de conservadorismo. 
Portanto, o que se observa naquele período, em particular na famosa greve de 1979, é que houve uma efervescência no movimento sindical dos professores no estado do Rio de Janeiro e uma preocupação com o protagonismo das mulheres, abrindo espaço para as questões de gênero nas discussões das professoras, tema totalmente ocultado durante os governos militares.

Assim, em greve conjunta em 1979, municipal e estadual, o SEPE apresenta resultados importantes nas reivindicações salariais do magistério, marcando um novo momento de participação da sociedade civil. Naquele episódio de avanço das conquistas sindicais, o que se observa é que despontou como maior liderança feminina, a professora Hildézia de Medeiros.

Ao longo dessa investigação, buscamos demarcar as possíveis contradições na formação desse sujeito, a nova mulher e professora, nos anos 1980, marcados pela abertura política e a promulgação de uma nova constituição federal em 1988, denominada como a Constituição Cidadã, que garante e amplia os direitos políticos e civis. Para Hildézia, basicamente as professoras nesse período eram brancas e eram, em sua maioria, oriundas de famílias de classe média, o que justificaria a manutenção da UPPE, que representaria uma visão mais tradicional quanto ao papel do magistério feminino das séries iniciais. Segundo a entrevistada, algumas professoras se sentiam mais próximas desse modelo antigo, herdado de suas mães e avós.

Enquanto, por outro lado, assinala também o surgimento de um novo magistério, não mais como profissão sacralizada, um caminho de renúncia e de abnegação, mas como categoria profissional de luta. Entre rupturas e permanências, assinala o surgimento de uma nova matriz identitária dessa mulher professora, daquela década, em meio ao processo de redemocratização do país.

Hildézia destacou que durante o primeiro governo de Leonel Brizola ${ }^{2}$ (1983 - $1986^{3}$ ) foi de grande importância o diálogo com a historiadora Maria Yedda

\footnotetext{
${ }^{2}$ Nas eleições de 1982, ao final da ditadura, Leonel Brizola, do recém-criado PDT (Partido Democrático Trabalhista), concorreu e ganhou as eleições deste ano para o governo do Rio de Janeiro. Um acontecimento que pode ser destacado, nessas mesmas eleições, foi o que aconteceu com Sandra Cavalcanti, do PTB, que passou por uma tentativa de fraude
} 
Linhares, secretária municipal de educação, de 1983 - 1985) e estadual no ano de 1986.

Conforme o depoimento:

Enquanto CEP, sempre tivemos uma relação de respeito com ela. Conhecíamos Maria Yedda como uma professora, antes de ser secretária, emérita no campo da educação. No campo da educação à esquerda, não podemos esquecer disso [...] Ela foi um marco extremamente interessante, importante. Houve um investimento, uma incidência do governo Brizola na questão da educação, embora eles tenham sacralizado algumas coisas [...] Agora, claro, sabemos que se uma pessoa se submete a ser secretária de Estado, em nome da tal governabilidade, às vezes há algumas dificuldades mais sérias. [...] Do ponto de vista pedagógico, de visão de mundo, a Maria Yedda era uma pessoa com quem podíamos conversar (MATOS, 2017, p. 148).

À luz dessas memórias, a pesquisa também busca identificar como mulheres, historicamente educadas para a submissão, podem desenvolver um papel transformador na escola. Dessa forma, a partir das trajetórias formativas de mulheres professoras e sua militância política, analisamos a formação ideológica das professoras, particularmente quanto à questão do imaginário feminino. O recorte histórico da pesquisa abrange trajetos de mulheres entre 1970 e 1980 . O objeto da atual investigação nos traz um fazer histórico repleto de sentidos das mulheres daquela geração. Nas palavras de Simone Beauvoir (1967, p. 9), "ninguém nasce mulher: torna-se".

Para Foucault (2003), cada sociedade tem discursos que funcionam como verdadeiros, embora sempre haja rupturas e novas mentalidades em gestação. As principais instituições guardiãs do discurso de cada época têm sido a família, a igreja e a escola, transmitindo os valores "verdadeiros" daquela sociedade.

Em contraposição à manutenção da exclusividade dessas instituições historicamente destinadas às mulheres, a ação das mulheres brasileiras, para Chauí (1994), representa a alternativa de criação de espaços públicos onde se possa ter a liberdade de falar, escutar, ser ouvida. Sem espaço público não há política, não há movimento, as sociedades se congelam. Para a autora, o espaço é uma arena de

eleitoral - em que consistia na mudança de votos válidos em brancos e nulos - pela encarregada de contar os votos, a empresa Proconsult.

${ }^{3}$ Leonel Brizola foi o primeiro governador eleito pelo voto direto após o golpe militar de 1964. 
debates e de conflitos que vão possibilitar a ética e a política, levando à participação de todos os setores da sociedade, principalmente os que sofrem a exclusão historicamente constituída, como no caso, as mulheres.

Hildézia ressalta que uma luta não anula outra e se faz importante sempre lembrar nossa juventude de que é possível lutar por muitas causas e, principalmente, pelos que não têm suas vozes ouvidas na nossa sociedade. Ante tais reivindicações, não seria equívoco afirmar que ela tem como sua bandeira principal a luta pela educação pública de qualidade.

Mas, além das possíveis marcas, é o não-dito que é preciso desocultar, identificando e decodificando os enunciados representativos daquelas décadas. Por outro lado, nesse caminho de sentidos muitas vezes sem sentido, talvez se torne possível desvelar o discurso construtor da(s) identidade(s) docente(s) naquele período.

Tais narrativas e discursos, envoltos em diferentes linhas de pensamento, sobre o que viria a ser a escola republicana, servem como cimento e espelho das diversas épocas históricas, forjados em períodos autoritários e/ou momentos de transição democrática.

Portanto, temos como objetivo, também, identificar as ideias que povoaram o processo de construção do pensamento educacional fluminense, assinalando rupturas e permanências no comportamento daquele professorado. A partir desse inventário de uma geração, identificar pistas nas décadas 1970/80 que desvelem o cotidiano escolar fluminense, preservando essa história institucional.

Outro autor que contribui com essa nossa discussão é Barroso (2005) ${ }^{4}$, assinalando que "as várias imagens de professor se distribuem segundo dois eixos". Um marcado pela dimensão técnica, que definiria o profissionalismo e o segundo, assinalando um sentido de missão. A saber, um "maior ou menor grau de “altruísmo”, capacidade de intervenção social, compromisso político” (BARROSO, 2005, p. 181).

\footnotetext{
${ }^{4}$ João Barroso: professor entrevistado em meu pós-doutoramento, do Instituto de Educação (IE/UL) - Universidade de Lisboa.
} 
Caracterizando-se por essa capacidade de intervenção e compromisso político, a trajetória de nossa professora engajada e liderança sindical, fundamental na história do magistério fluminense, Hildézia, revela, portanto, sua enorme contribuição à educação pública, através não só de sua atuação como docente, mas, também, de sua participação pela democratização da formulação das políticas públicas educacionais, pela democratização da gestão e estruturação das escolas públicas fluminenses, bem como pelo fomento à formação de consciência política, com ênfase em classe e gênero, da categoria do magistério no Estado do Rio de Janeiro.

\section{Dodora Mota: da vivência comunitária à professora militante}

\section{[...] a escola também é lugar de conflito. (Dodora). ${ }^{5}$}

A escola como lugar de conflito, terreno democrático do contraditório que enriquece a aprendizagem: é desta forma que Maria das Dores Pereira Mota, a Dodora como é conhecida em seus círculos sociais, expressa uma breve síntese de suas concepções acerca deste espaço vivo em que se traduz o ambiente escolar.

Traz, em sua trajetória, as marcas de ser uma das fundadoras do Sindicato Estadual dos Profissionais da Educação, de ter sido, possivelmente, a primeira diretora de escola eleita no Estado do Rio de Janeiro e de ter tido um mandato de vereadora de esquerda numa das cidades operárias mais pesquisadas do Brasil, Volta Redonda.

Professora engajada e militante política determinada, desvelando seu repertório de memórias, torna explícita a relação com Hildézia de Medeiros, cuja trajetória visitamos inicialmente neste artigo. Entre iniciar sua participação mais ativa como base do movimento, passar à vanguarda e se consolidar como liderança, Dodora cita Hildézia Medeiros como uma forte referência, dentre outras companheiras que despontaram a partir da greve de 1979. Foi justamente através de

\footnotetext{
${ }^{5}$ Entrevista concedida em 31/05/2011.
} 
Hildézia que Dodora vivencia seu primeiro contato com o debate feminista, na ocasião do primeiro encontro de mulheres do CEP. E mais tarde, por iniciativa desta mesma companheira junto à diretoria do sindicato e à fotógrafa Cláudia Ferreira, Dodora serve de modelo ao projeto que registra um dia na vida de uma professora, em que aspectos peculiares de suas jornadas múltiplas são desvelados por meio do registro fotográfico conjugado ao texto literário, dando origem, como já colocado anteriormente, à exposição "O sol por testemunha”. Observamos, dessa forma, onde os caminhos de Dodora se cruzam com os de Hildézia, esta também declarada admiradora da companheira de profissão e luta, do território da militância sindical para a vida.

Portanto, buscamos agora discorrer sobre as lembranças escolares pertinentes à trajetória de Dodora. Ao recompormos essa trajetória, baseada especialmente na memória e na história oral, a escola, a educação e a luta sindical docente se traduzem numa essência e lembram o que nos pontua Pollak (1992, p. 201), quando expõe sobre os elementos constitutivos da memória, individual ou coletiva, caracterizados por acontecimentos, personagens e lugares. Suscetível, também, a processos de projeção ou transferência, em função da construção cultural mediada pelo outro.

Nascida em Minas Gerais no ano de 1946, no pequeno distrito rural da cidade de Abre Campo, conhecido como Granada, passou a infância no município de Caputira, na companhia dos pais, irmãos e avós maternos, enriquecida pelo convívio de tios, tias, primos e primas, numa família em que conversar sobre política era atividade cotidiana. Nesse embalo, apreende das histórias contadas pela mãe, Jurandina Muniz Pereira, informações sobre um avô que se envolvia na política local e teria comemorado a vitória da Aliança Liberal na Revolução de 1930. E, embora Halbwachs (1990) pondere que uma lembrança descrita pelos outros não é uma lembrança própria, afirma também que os testemunhos auxiliam na recomposição das recordações. Sendo assim, para Dodora, a herança do gosto pela política, observada nos efervescentes debates cotidianos entre seus doze tios maternos, ainda repercute significativamente em sua memória.

[...] a memória individual existe, mas ela está enraizada dentro dos quadros diversos que a simultaneidade ou a contingência reaproxima momentaneamente. A rememoração pessoal situa-se na encruzilhada das malhas de solidariedades 
múltiplas dentro das quais estamos engajados. Nada escapa à trama sincrônica da existência social atual, e é da combinação destes diversos elementos que pode emergir esta forma que chamamos de lembrança [...] (HALBWACHS, 1990, p. 14).

Assim, nota-se que é sobre esse universo de vivência familiar ampliada que surgem relatos sobre as primeiras observações da menina Dodora a respeito de práticas comunitárias, nas quais a família compartilha preocupações, alegrias e gestos solidários. Como Adélia Prado (1976), em seu Licença Poética, traduz sobre a persistência de uma alegria herdada quando diz que sua tristeza não tem pedigree, mas a raiz de sua vontade de alegria vai ao seu mil avô.

Em contrapartida, lembra a escola daquele tempo, na pequena Caputira, como local de onde fugia para "matar aulas" ao pé da mangueira, embora também espaço de encontro e "lugar de prazer", de onde guarda ainda os nomes das primeiras professoras, Maria Celso e Maria de Lourdes. Mas, também, as varadas na mão que leva outrora, no provável intuito de "correção" dos comportamentos julgados livres por demais para a conduta de uma menina, considerando o contexto da década de 1950, quando ainda era observada uma concepção de educação majoritariamente tradicional e patriarcal, baseada em ordem, castigos e subjugação feminina. "A precaução é um ingrediente antigo na educação das mulheres. 'As meninas devem ser refreadas desde cedo', segundo Rousseau”, analisa Perrot (2007, p. 42), ao discorrer sobre a história das mulheres no que se refere ao poder exercido sobre seus corpos.

É partindo de um emaranhado de relações, então, que localizamos no seio familiar dinâmico, vivo e solidário, os primeiros agentes significativos no processo inicial de sua educação. Considerando, porém, que os itinerários formativos da menina mineira - depois professora incomodada com a negação do espaço de conflito que cabe à escola — se cruzam com outras dimensões, numa composição caleidoscópica sobre a vida. Como aquelas relacionadas à sua atuação na Igreja Católica progressista, na luta por democratização nas redes públicas de educação, na fundação do $\mathrm{SEPE}^{6}$ - núcleo de Volta Redonda, bem como na vida política da

\footnotetext{
${ }^{6}$ O SEPE organiza-se através de regionais, no âmbito da capital do Estado, e de núcleos, que correspondem a um ou mais municípios do interior. O núcleo de Volta Redonda é um dos núcleos da região sul-fluminense.
} 
própria cidade, no que tange às narrativas envoltas nas lutas operárias da $\mathrm{CSN}^{7}$ e ao mandato de vereadora pelo Partido dos Trabalhadores.

Naquele período, entre as décadas de 1940 e 1960, em um Brasil de contrastes e desigualdades extremos, ocorre a crise política que culmina no desfecho trágico de seu presidente e o país permanece suscetível às pressões e interesses de determinados setores nacionais e internacionais. Dá-se a abertura da economia ao capital estrangeiro, portas abertas às multinacionais, o crescimento e endividamento econômico. O contexto favorece a fundação de Volta Redonda, a cidade-destino de Dodora e sua família, no Estado do Rio de Janeiro, conhecida por ter sua origem motivada pela criação da Companhia Siderúrgica Nacional (CSN), indústria produtora de aço construída a partir da política varguista de industrialização, no período de 1942 a 1946, e também polo fundamental do movimento sindical no Brasil. Nasce a CSN, nasce Volta Redonda ${ }^{8}$, e o encontro de Dodora com a cidade e com tudo o que ela representa produz efeitos duradouros, sobre os quais relata: "cresci junto com essa cidade".

Da mãe, além da memória do controle excessivo, especialmente sobre filhas mulheres, ao que respondia com um comportamento rebelde e estratégias de fugas na adolescência, subvertendo opressões, também leva a lembrança da preservação das histórias familiares, da prática de guardiã e disseminadora da herança histórica deste grupo social, como numa "missão" comum às mulheres de todos os tempos e lugares. Perrot (2005) nos fala sobre

Por força das coisas, ao menos para as mulheres de outrora e para o que resta do passado nas mulheres de hoje (e que não é pouco), é uma memória do privado, voltada para a família e para o íntimo, aos quais elas estão de certa forma relegadas por convenção e posição. Cabe às mulheres conservar os traços das infâncias em que elas são governantas. Cabe a elas a transmissão das histórias de família, feita geralmente de mãe para filha [...] A memória das mulheres é verbo.

\footnotetext{
${ }^{7}$ Companhia Siderúrgica Nacional, até então a maior empresa pública de siderurgia do Brasil, construída no local que se constituiu como o município de Volta Redonda, o que proporcionou um cenário de lutas sindicais e uma história operária muito específica à cidade.

${ }^{8}$ A Companhia (CSN) é criada através do decreto-lei n. 3002, de 30 de janeiro de 1941 e inicia seu funcionamento parcial em 1946. A localidade de Volta Redonda, até então distrito de Barra Mansa, consegue sua emancipação e torna-se município em 1954. Dodora e sua família chegaram à cidade em 1955.
} 
Ela está ligada à oralidade das sociedades tradicionais que the confiavam a missão de contadora da comunidade da aldeia (PERROT, 2005, p. 39-40).

Por outro lado, do pai carrega a imagem do homem trabalhador, de cujo convívio extraía comentários sobre as condições concretas que se estabeleciam no ambiente de trabalho, especialmente quando ingressou como operário da CSN. Conversas do cotidiano que, somando-se à repercussão das memórias familiares anteriores, introduziam a temática política em seu imaginário.

Ao se estabelecer em Volta Redonda e criar novos vínculos, a família, que se guiava por uma orientação religiosa cristã católica, inicia novas práticas societárias no âmbito da Igreja, aspecto que será determinante para a trajetória de Dodora culminar nos papéis sociais delineados ao longo de sua vida.

- Eu vim para Volta Redonda com 9 anos, então a minha participação na política se deu muito mais através da Igreja do que da família. No bairro onde nós morávamos, na rua São João, tinha uma igreja muito atuante [...] foi organizado um grupo de jovens que se chamava ACA], Associação Católica Juvenil, [...] a gente discutia muito o evangelho, analisava, mas sempre à luz da realidade, a gente usava também o método da JOC, que era o Ver-Julgar-Agir. Então, isso, a minha formação política, a linha de justiça, de igualdade, vem muito mais dessa formação ${ }^{9}$.

Em seus relatos, Dodora explicita o caráter socializador e educativo de sua experiência religiosa. A intensa rotina de leitura crítica do evangelho baseada na análise da realidade e na prática social e o convívio em grupos sociais da igreja e do bairro foram a concretização de relações comunitárias e de um itinerário formativo de sua consciência política, nas fases que compreendiam entre a infância e o início da vida adulta.

Além disso, se refere à JOC, Juventude Operária Católica, e seu método de leitura e análise do evangelho, "Ver-Julgar-Agir", como forte influência e base metodológica de sua formação política. Cabe compreender do que se tratava o método Ver-Julgar-Agir, segundo Baptista (2014, p. 242) “A inspiração imediata nasceu do método de revisão de vida da Ação Católica — Ver, Julgar e Agir criado pelo Pe. Joseph Cardijn no trabalho com jovens operários", que se tratava de

\footnotetext{
${ }^{9}$ Entrevista concedida em 31/05/2011.
} 
um exercício dialético "relacionando Evangelho e Vida, realidade histórica e fé, teoria e prática”. Refere-se à prática política a partir de uma concepção da práxis, que se desdobrava em três implicações: o engajamento na práxis, o engajamento para a práxis e o engajamento pela práxis. Disso depreende-se que esta metodologia, pensada no cerne da Teologia da Libertação, caracterizava-se por participação integrada nas comunidades e grupos, por opção clara pelos pobres e por pautas sociais que permitiam desenvolver estrategicamente a perspectiva da libertação e a realização de um movimento crítico contínuo de "análise e verificação".

Nos perguntamos, portanto, em que momento de seu processo formativo Dodora vivencia uma superação da concepção cristã-católica conservadora sobre o mundo e a vida, de modo a exprimir uma outra visão sobre a realidade, mais crítica e próxima de uma consciência de classe marxista?

Algumas evidências sinalizam para as interações e experiências que mais repercutiram nesta fase inicial de sua vida, dentre elas, a participação nas instâncias desta Igreja "renovada" pós Concílio Vaticano II e algumas das escolas frequentadas ao longo de sua escolaridade, bem como para sua atuação sindical e política posteriormente.

$\mathrm{Na}$ reconstituição dessa trama de lembranças, na qual retalhos da memória são reexaminados, surge o que teria sido a primeira percepção de sua condição de classe. Ao terminar o ginasial, Dodora acompanha os colegas numa seleção para a escola privada local, o Colégio Macedo Soares. No entanto, após um período de curso, se depara com as dificuldades financeiras da família para manter as mensalidades, ao mesmo tempo em que se descobre interessada pela opção do Curso Normal, oferecido em sua escola anterior, o Ginásio Paulo Monteiro Mendes, “[...] terminei o ginásio no Paulo Mendes [...] era aquela escola onde 'trabalhava' todos os filhos dos trabalhadores da CSN, era no Rosário onde estudavam os filhos da elite da CSN..."10.

Dodora relembra episódios de sua escolarização e da formação na Igreja que, a nosso ver, contribuíram para a educação do olhar crítico sobre os fatos e as coisas.

\footnotetext{
${ }^{10}$ Entrevista concedida em 31/05/2011. No lugar de 'trabalhava', subentendemos 'estudava'.
} 
Tais vivências se constituíam em espaços onde crianças e jovens eram chamados a ter participação ativa e reflexiva, inclusive através da linguagem teatral. O trabalho com teatro parece ter aberto horizontes para uma leitura mais abrangente dos textos e para um exercício de leitura do mundo. Se reporta, ainda, a outros docentes que se utilizaram do teatro como estratégia didática, a qual ela mesma recorre em sua militância sindical e política.

Quanto às memórias mais relacionadas à escola, Dodora destaca um episódio que marcou sua visão acerca da atuação docente. No dia de sua formatura do antigo Admissão ${ }^{11}$, correspondente ao quinto ano de escolaridade com atribuição de garantir o ingresso no ensino médio da época (dividido em ginasial e colegial), uma forte passeata com a participação dos docentes tomava as ruas da cidade por conta do atraso prolongado de salários do funcionalismo. Embora ainda não houvesse uma estrutura sindical específica consolidada, as manifestações se organizavam aparentemente pela base, através de lideranças ou associações pulverizadas. $O$ fato se deu no governo municipal de César Cândido Lemos, cujo mandato durou apenas um ano e dois meses, entre janeiro de 1959 e março de 1960, tendo sido o primeiro prefeito do Brasil a sofrer um processo de impedimento, em decorrência da acusação de incompetência administrativa e do atraso salarial do funcionalismo por nove meses. Cita, também, debates relacionados à aprovação da LDB 4024/61, “eu me lembro deles no Colégio Paulo Mendes discutindo muito isso". Ainda que não tenha testemunhado greves de seus professores ou participado de manifestações de rua, a conotação contestatória e engajada da atuação de muitos destes docentes marcou sua concepção de educação.

Da mesma forma, Dodora observa a movimentação estudantil local, que se dá através de comissões: "participei de muitos grupos reivindicatórios na escola", e da AVE (Associação Volta-redondense de Estudantes), pautando, principalmente, o

\footnotetext{
11 “O exame de admissão ao ginásio foi instituído, em nível nacional, no ano de 1931, e perdurou oficialmente até a promulgação da Lei $n^{\circ} 5692 / 71$, quando foi instaurado 0 ensino obrigatório de $1^{\circ}$ grau, com duração de oito anos, integrando os cursos primário e ginásio em um único ciclo de estudos." (ABREU; MINHOTO, 2012, p. 108). Ressalta-se que algumas escolas realizavam um ano preparatório, ao final do primário, para o exame que se intitulava comumente por Admissão.
} 
passe livre, então conquistado para todos os estudantes, fato destacado com orgulho “em Volta Redonda nós tínhamos passe livre".

À medida que Dodora chega à juventude, imersa no contexto histórico que se dá entre o período de intensa atuação dos movimentos sociais pré-64 e, posteriormente, o período do regime autoritário instituído pelo Golpe Civil-militar, se fortalecem, também, mudanças que já vinham se colocando na trama de tensões internas da Igreja Católica em diálogo com sua base popular. Enquanto a igreja hierárquica utilizava-se sempre de estratégias de manutenção de seus espaços de poder $^{12}$, a igreja popular, ou o que entendemos por uma base de atuação dos leigos engajados, caminha no sentido de alargar o processo de conformação de uma teologia que opta pelos pobres, inspirada pelo Concílio Vaticano II, em superação ao que já havia enquanto doutrina social católica. Logo, ante todos esses elementos, constatamos que o percurso formativo de Dodora encontra-se fundamentado nessa perspectiva, o que ganha luz através de suas próprias palavras:

[...] isso me levou à participação política e com as comunidades de base aprofundou a minha visão de esquerda na política [...] quem me levou a ser hoje uma socialista 'foi ' as comunidades de base, o trabalho de comunidade, da Teologia da Libertação. Eu não tenho uma formação marxista, eu tenho uma formação católica, da Teologia da Libertação. $^{13}$

Ao afirmar que não tem "formação marxista", Dodora remete à experiência eclesial que se configurava como lembrança de uma herança mais imediata e visível. No entanto, aparentemente não percebe que "A influência do pensamento marxista é clara, mas numa apropriação crítica” (BAPTISTA, 2014, p. 243). Como afirmado pelos autores que pensaram a TdL (Teologia da Libertação), tratava-se de uma opção clara no mundo político, uma "opção revolucionária e socialista" (GUTIERREZ apud BAPTISTA, 2014).

Nesse enquadramento destacamos uma figura central para Dodora: Dom Waldyr Calheiros de Novaes, o então arcebispo da Diocese de Barra do Piraí. “Chegou D. Waldyr [...] luta contra a Ditadura, aí já tinha o Golpe Militar [...] esse

\footnotetext{
${ }^{12}$ Inclusive, a Igreja estabelece relações com o Estado brasileiro para resguardar sua base nos novos tempos de industrialização frente aos desafios do mundo do trabalho.

${ }^{13}$ Entrevista concedida em 31/05/2011.
} 
sentimento de justiça e de igualdade se aprofundou mais diante das atrocidades" ${ }^{\text {"14 }}$. É dessa maneira, pois, que Dodora faz sua primeira menção ao bispo de sua diocese, conhecido como Bispo Vermelho, que chega à cidade em 1966. Junto a ele, conforme vemos em Soares (2009), trabalharam diversos padres-operários, que encarnavam em sua vida cotidiana não apenas os votos de sacerdotes de uma instituição religiosa, mas também a experiência real do universo fabril.

Dodora relata, inclusive, que sua percepção do impacto do fechamento do Regime, nesse momento, se dá mais claramente ao perceber o cerceamento dos espaços de debate, as dificuldades em realizar reuniões dos grupos de jovens, uma preocupação muito maior com os jovens por parte dos pais e familiares, a prisão de amigos e a atuação veemente de D. Waldyr na defesa dos direitos de trabalhadores e no enfrentamento às arbitrariedades das autoridades militares.

Logo, em vista desse conjunto de ações que caracterizaram os primeiros anos de D. Waldyr na Diocese de Barra do Piraí/Volta Redonda, e sobre os quais os depoimentos de Dodora jogam luz, não é impróprio afirmar que sua atuação e formação na esfera da Igreja Católica lhe forneceram, inclusive, condições de analisar e se posicionar criticamente quanto ao regime político recém-instalado através de um Golpe Civil-militar. Dodora ressalta que sua participação no combate à Ditadura se dava como base da Igreja, participando das manifestações e atividades destinadas a pressionar o Estado - bem como, posteriormente, do Movimento contra a Carestia.

Das motivações iniciais para optar pela carreira docente estava a possibilidade de trabalhar com crianças, mas é possível notar um forte apelo das interlocuções diversas, na Igreja e na educação formal, que se deram na perspectiva da educação popular. Ao vivenciar e reproduzir práticas baseadas no método VerJulgar-Agir, experiências com metodologia teatral e o engajamento coletivo em espaços cuja abordagem pretendia despertar consciência crítica, como os grupos de jovens daquele contexto, alimentavam um envolvimento embrionário com o processo educativo. Soares (2009, p.2) destaca, inclusive, que "o papel educativo é certamente uma das características marcantes das Cebs. Vários autores defendem as

\footnotetext{
${ }^{14}$ Idem, 2011.
} 
Cebs como o mais vasto trabalho de educação popular, não promovido pelo Estado, neste século no Brasil. (Wanderley, 1981)".

Portanto, para o que Dodora talvez não tenha se atentado é de que já se dá o exercício de uma prática educativa ao longo de suas diversas atividades enquanto jovem estudante e leiga católica. Sendo assim, expressa identificação com temáticas abordadas na formação do magistério em nível médio: filosofia, psicologia, sociologia, as ciências que pensavam a sociedade, suas relações e o desenvolvimento humano ratificam nela a certeza da escolha.

Considerando a reconstituição de elementos importantes em seu trajeto formativo, ressaltamos, ainda, sua contribuição para a educação pública fluminense. Professora sempre engajada politicamente, participa de coordenações e setores pedagógicos em âmbito municipal (Volta Redonda), na elaboração de planejamentos curriculares e formação de professores na perspectiva da educação libertadora de Paulo Freire, e estadual (RJ), tendo integrado equipes vinculadas ao Laboratório de Currículos $^{15}$. É eleita diretora de escola, num processo interno fortemente democrático e pioneiro, podendo ter sido a primeira diretora eleita no Estado do Rio de Janeiro, realizando uma gestão baseada em princípios democráticos de priorização do colegiado como instância de decisão. Vivencia, também, um mandato de vereadora, comprometido com as lutas sociais e sindicais da cidade, assim como com a garantia da oferta de educação pública e dos direitos de seus profissionais. É com uma convicção que Dodora define esse período de sua vida, “[...] sempre participei de alguma organização, sempre organizada", ainda que reconhecendo os limites e contradições que a própria formação moral e religiosa pudesse lhe imputar.

\section{Considerações finais}

\footnotetext{
15 "Assim, para solucionar esses problemas e prover a democratização da instituição escolar, entendida não somente em termos quantitativos, mas sobretudo, no sentido de reduzir as desigualdades sociais no atendimento escolar, a Secretaria Estadual de Educação e Cultura cria o Laboratório de Currículos, órgão responsável pela pesquisa, formulação e implementação de propostas de renovação pedagógica e de política educacional. [...] Foi pautada na experiência brasileira de pesquisas em cidades-laboratório que a Secretaria Estadual de Educação e Cultura buscou inspiração para gerar o modelo do Laboratório de Currículos" (FARIA e LOBO, 2005, p. 2).
} 


\section{Caminhos em aberto}

Nas páginas escritas por uns e por outros, as vozes estavam presentes. No estudo e no silêncio tentamos escutá-las e fazê-las nossas. As dívidas serão, então, múltiplas e recíprocas.

(Roger Chartier) ${ }^{16}$.

Se levarmos em conta a frágil tradição democrática brasileira e a ruptura ainda recente ocorrida em 1964, devemos assinalar que pouco se avançou após a Constituição Federal de 1988 no que se refere aos direitos das mulheres, crianças, jovens, povos originários e população LGBT. As práticas opressoras desenvolvidas ao longo da nossa história, em particular pela Igreja e pelo Estado, não serão facilmente superadas.

Considerando o contexto de pandemia mundial, pelo qual seguimos passando neste ano de 2020, já é possível constatar o aumento real da exploração de gênero, visto que as mulheres são as que mais se responsabilizam pelas tarefas domésticas de manutenção da sobrevivência e reprodução social da vida. O que significa que, em uma condição de distanciamento social imposto (confinamento), o volume desse tipo de trabalho torna-se muito maior.

Historicamente, as mulheres, foram escolhidas para representar os papéis de esposa, mãe e professora, "adestradas" para exercer função de reprodutoras de um saber instituído, que convinha à sociedade brasileira de nossas mães e avós.

Assim, professoras, durante décadas, representaram a função de defensoras das normas e modelos masculinos que a sociedade capitalista patriarcal apregoava, tendo em vista manter sua hegemonia.

Ressalta-se, dessa forma, a importância para o campo historiográfico da análise e preservação da história institucional, organizando a recuperação e preservação de relatos, documentos, objetos e materiais que identifiquem aspectos significativos dos sistemas públicos de ensino. Ressalta-se, também, a importância

\footnotetext{
${ }^{16}$ Citação extraída da palestra intitulada Voces Paginarum, apresentada no Rio de Janeiro, na PUC/Rio em setembro de 2005, por ocasião do Colóquio Roger Chartier - Apropriações de um pensamento no Brasil.
} 
da valorização do campo de pesquisa da história das mulheres, através do qual se pode compreender o caráter de gênero que perpassa a história da educação e o impacto da formação e trajetória de mulheres nessa dimensão, fortalecendo assim projetos e iniciativas que visam combater a invisibilização histórica a que vêm sendo submetidas.

Ler/reler falas e narrativas de mulheres professoras, militantes políticas, como Hildézia e Dodora, vem nos possibilitando adentrar em um universo que se permite desvelar, apontando possíveis tensões e contradições que ainda permeiam o cotidiano escolar fluminense, numa percepção da escola pública enquanto o lócus/território da política. Enfim, um olhar sobre a educação, enquanto "paixão política", identificando e desocultando o perfil das mulheres professoras que se tornam militantes.

Em tempos de extremo conservadorismo em nosso país, destacamos a importância da autonomia docente, incentivando estudos no campo da História da Educação, que analisem memórias/trajetórias, não só dos professores (as) das escolas públicas, assim como das demais instituições escolares.

Logo, reafirmamos essa relevância com as palavras de Tavares (2016):

Toda leitura de mundo tende, na maioria das vezes, a nos aproximar de antigos e novos espaços, sujeitos anônimos, ou já conhecidos, os quais carregam consigo experiências, expectativas e projetos. Na verdade, são homens e mulheres instauradores de valores, construtores de uma memória, protagonistas de um verdadeiro labirinto, no qual, para juntarmos suas peças, precisamos combinar certas doses de coerência com porções bem equilibradas de ousadia. Assim é quando pensamos no trabalho do historiador e dos/as pesquisadores/as que trabalham com pesquisas na área da História da Educação. O/a pesquisador/a na reconstrução/ reconstituição dos fatos históricos obriga-se a escolher um semnúmero de pistas, fontes, reconstruindo o passado, seleciona e ordena fatos que o induzem a aventurar-se na produção de uma verdade criada, imaginada, tecida pelas linhas tênues do tempo. Um tempo individual trabalhado em função de um tempo coletivo, social (TAVARES, 2016).

Dessa forma, compreendendo as trajetórias aqui investigadas nesse tempo coletivo/social, constatamos que uma vez que Hildézia é identificada como liderança que fomentava iniciativas que faziam alusão às questões de gênero no interior da profissão, é possível inferir que seu papel na história do sindicato e da educação fluminense foi fundamental para a consolidação da entidade, entendendo sua concretude organizativa para a categoria amplamente feminina, mas também 
para que se viabilizassem espaços no correr da luta sindical, para reflexões mais aprofundadas e formação de consciência política, no que se refere à pertinência da luta feminista no interior da profissão. Assim como Dodora, referenciada também em Hildézia, constituindo-se posteriormente como liderança e participando ativamente das respectivas ações e debates, contribui decisivamente para a ampliação de uma consciência de classe e de gênero. Como nos diz Perrot, "o sindicalismo significa alguma coisa para as mulheres, sendo mais acessível que a política porque é mais próximo de suas práticas e preocupações concretas, é algo que vai paralelo às suas vidas" (1996, p. 199).

Com a convicção da importância fundamental do olhar sobre as trajetórias de Hildézia e Dodora para a subversão da educação patriarcal de mulheres nos dias atuais, como também no sentido de forjar identidades docentes críticas e engajadas, endossamos seus lemas de vida, os quais nos remetem à certeza de que é preciso sonhar e lutar, irredutivelmente, outro mundo, em qualquer circunstância.

\section{Referências}

ABreU, G. S. A.; MINHOTO, M. A. P. Política de admissão ao ginásio (1931-1945): conteúdos e forma revelam segmentação do primário. Revista HISTEDBR, Campinas, n. 46, p. 107-118, 2012.

ANDRADE, M. Prefácio interessantíssimo [a Paulicéia desvairada]. In: ANDRADE, Mário. Poesias completas. Belo Horizonte: Itatiaia. p.17-31. 1980.

BARROSO, J. Políticas Educativas e Organizações Escolar - Temas Universitários. Lisboa: Universidade Aberta, 2005.

BAPTISTA, P. A. N. Religião, política e Teologia da Libertação: trajetória e desafios. Revista Pistis Praxis, Curitiba, v. 6, n. 1, p. 229-254, jan./abr. 2014.

BEISIEGEL, C. R. A política de educação de jovens e adultos analfabetos no Brasil. In: Gestão democrática da educação: desafios contemporâneos. [S.l: s.n.], 2005.

BEAUVOIR, S. O Segundo Sexo, v. II. Tradução Sérgio Milliet. São Paulo: Difusão Europeia do Livro, 1967. 
BIGNOTTO, N. Pensar a República. Belo Horizonte: Editora UFMG, 2002.

BOSI, E. Memória e sociedade: lembranças de velhos. São Paulo: Ed. T.A. Queiroz, 1979.

CARLOS, A.; SANTOS, M. A invenção do Brasil. Ensaios de história e cultura. Rio de Janeiro: Editora UFRJ, 2007.

CHARTIER, R. A beira da falésia: a história: entre certezas e inquietude. Porto Alegre: Ed. UFRGS, 2002.

CHAUÍ, M. Raízes teológicas do populismo no Brasil: teocracia dos dominantes, messianismo dos dominados. In: DAGNINO, E. Os anos 90, política e sociedade no Brasil. São Paulo: Brasiliense, 1994.

FARIA, L.; LOBO, Y. Identidade e campo de produção: o Laboratório de Currículos da Secretaria de Estado de Educação e Cultura do Rio de Janeiro (1975-79). In: GT: História da Educação, n. 02. 28ª Reunião Anual da ANPEd, 2005.

FARIA, L.; SOUZA, S. (Org.). Ecos e Memórias da Escola Fluminense. Rio de Janeiro: Quartet, 2008.

FARIA, L. Chaguismo e brizolismo: territorialidades políticas da escola fluminense. Rio de Janeiro: Quartet, 2011.

FARIA, L. Ideologia e utopia nos anos 60. Um olhar feminino: Editora UERJ, 1997; 2017.

FARIA, L. Memória Política e Docência: Professores Militantes no estado do Rio de Janeiro. In: MONTEIRO, S. R. (Org) Diversidades redes de sociabilidade e bistória de vida. Curitiba: CRV, 2018.

FERNANDES, R. Educação, uma frente de luta. Lisboa: Livros Horizonte, 1977.

FOUCAULT, M. História da sexualidade: o uso dos prazeres. Rio de Janeiro: Graal, 2003.

HALBWACHS, M. A memória coletiva. São Paulo: Ed. Revista dos Tribunais LTDA, 1990.

LOZANO, J. E. A. Prática e estilos de pesquisa na história oral contemporânea. In: AMADO, J. e FERREIRA, M. de M. (org.). Usos e abusos da história oral. Rio de Janeiro: Ed. Fundação Getúlio Vargas, 1998.

MARTINS, T. R. Memórias militantes: a trajetória de Dodora Mota na luta pela educação pública. 2019. 156 p. Orientadora: Lia Ciomar Macedo de Faria. Dissertação (Mestrado em Educação) - Universidade do Estado do Rio de Janeiro, Rio de Janeiro, 2019.

MATOS, S. C. M. Memórias e diálogos com a Educação Integral: o legado de Maria Yedda Leite Linhares (1983-1986). 2017. 209 f. Orientadora: Lia Ciomar Macedo de Faria. Tese (Doutorado em Educação) - Faculdade de Educação, Universidade do Estado do Rio de Janeiro, Rio de Janeiro, 2017.

MATOS, SHEILA C. M.; FARIA, L. C. M. A intelectual Maria Yedda Leite Linhares: memórias e diálogos (anos 1980/ Rio de Janeiro). Revista Brasileira de Educação (RBE), v. 24, e240026, 2019. 
MONTEIRO, S.; BERKENBROCK, B. (Org.). Diversidades, redes de sociabilidade e história de vida: outros modos de narrar. Curitiba: CRV, 2018.

NASCIMENTO, J. C. (Org.). Percursos e narrativas de mulheres professoras. Curitiba: CRV, 2017.

NÓVOA, A. A formação de professoras e profissão docente. In: NÓVOA, A. (coord.) Os professores e Sua formação. Lisboa: Dom Quixote, 1995.

PERROT, M. A história feita de greves, excluídos \& mulheres. Tempo Social, Rev. Sociologia, USP, São Paulo, v. 8, n. 2, p. 191-200, 1996. (Entrevista concedida a HALL, M.; NEGRO, A.; COSTA, H.; FONTES, P.; XAVIER, R.).

PERROT, M. Traços/Práticas da memória feminina. In: PERROT, Michelle. As mulheres ou os silêncios da história, Bauru, EDUSC, 2005.

PERROT, M. Práticas da memória femininas. In: SCOTT, Joan. Histórias das Mulheres. São Paulo: Contexto, 2007.

PERROT, M. Minha história das mulheres. São Paulo: Contexto, 2007.

POLLAK, Michael. Memória e identidade social. Estudos Históricos, Rio de Janeiro, v. 5, no 10, 1992. P. 200-212.

SADI, D. R. (Org.). Associativismo e sindicalismo em educação: organizações lutas. Brasília: Paralelo15, 2011.

SANTOS, B. S. A cruel pedagogia do virus. Coimbra: Almedina, 2020.

SOARES, P. C. A atuação das Cebs em Volta Redonda (1974-1979). Revista Nures, São Paulo, n. 13, set./dez. 2009.

TAVARES, M. T. G.; BRAGANÇA, I. F. S. (Org.) Voz̧es da Educação 20 anos: memória, políticas e formação docente. Niterói: Intertexto, 2016.

TEODORO, A. A construção Política da Educação. Estado, mudança social e políticas educativas no Portugal contemporâneo. Lisboa: Edições Afrontamento, 2011.

RECEBIDO: 29/08/2020

APROVADO: 03/10/2020

RECEIVED: 08/29/2020

APPROVED: $10 / 03 / 2020$

RECIBIDO: $29 / 08 / 2020$

APROBADO: 03/10/2020 